\title{
Olfactory Dysfunction in Nasal Bone Fracture
}

\author{
Sug Won Kim, \\ Beom Park, \\ Tae Geun Lee, \\ Ji Ye Kim
}

Department of Plastic and Reconstructive Surgery, Wonju College of Medicine, Yonsei University, Wonju, Korea

No potential conflict of interest relevant to this article was reported.

\begin{abstract}
Background: All nasal bone fractures have the potential for worsening of olfactory function. However, few studies have studied the olfactory outcomes following reduction of nasal bone fractures. This study evaluates posttraumatic olfactory dysfunction in patients with nasal bone fracture before and after closed reduction.

Methods: A prospective study was conducted for all patients presenting with nasal bone fracture $(n=97)$. Each patient consenting to the study underwent the Korean version of Sniffin' Sticks test (KVSS II) before operation and at 6 month after closed reduction. The nasal fractures were divided according to the nasal bone fracture classification by Haug and Prather (Types I-IV). The olfactory scores were compared across fracture types and between preoperative and postoperative settings.

Results: Olfactory dysfunction was frequent after nasal fracture (45/97, 46.4\%). Our olfactory assessment using the KVSS II test revealed that fracture reduction was not associated with improvements in the mean test score in Type I or Type II fractures. More specifically, the mean posttraumatic Threshold, discrimination and identification score decreased from 28.8 points prior to operation to 23.1 point at 6 months for Type II fracture with septal fracture.

Conclusion: Our study has revealed two alarming trends regarding post-nasal fracture olfactory dysfunction. First, our study demonstrated that almost half $(46.4 \%)$ of nasal fracture patients experience posttraumatic olfactory dysfunction. Second, closed reduction of these fractures does not lead to improvements olfaction at 6 months, which suggest that olfactory dysfunction is probably due to factors other than the fracture itself. The association should be further explored between injuries that lead to nasal fracture and the mechanism behind posttraumatic olfactory dysfunction.
\end{abstract}

Keywords: Olfactory nerve / Skull fracture / Smell

\section{INTRODUCTION}

The nasal bone is the most common site of facial fracture and is the third most common fracture site for the whole body. Nasal bone fractures occur either alone or with other facial bone fractures and account for approximately 40 percent of all facial fractures [1-3]. Because of its central location and anterior projection on the face, the nasal complex is susceptible in head or facial traumatic injury. The management of nasal fracture differs according

\section{Correspondence: Sug Won Kim}

Department of Plastic and Reconstructive Surgery, Wonju Christian Hospital, Yonsei University Wonju College of Medicine, 20 Ilsan-ro, Wonju 26426, Korea E-mail: sugwonkim@gmail.com

*The authors thank Dr. Aram Harijan for his insightful comments and assistance in the language of this manuscript.

Received May 15, 2017 / Revised June 13, 2017 / Accepted June 13, 2017 to various patient factors and surgeon preference [1-6]. However, the vast majority of nasal bone fractures are treated by closed reduction with rates of successful reduction ranging between $70 \%$ and $95 \%$ [1,5,7-10]. Posttraumatic olfactory dysfunction is a recognizable concern in these patients [11-19]. The decline in olfactory function can be caused by disruption of sinus tract, olfactory nerve injury, injury to the connections between central olfactory structures as well as indirect airflow disturbance by factors associated with operation such as packing material [16]. Olfactory impairment as a result of nasal bone fracture may range from hyposmia (decrease in odor detection ability) to anosmia (inability to detect odors) $[13,14,16]$. In this study, we evaluate olfactory function in patients with nasal fracture before and after closed reduction. 


\section{METHODS}

\section{Study design and data collection}

A single-institution prospective cohort study was performed for all patients presenting with facial injury between March 2013 and May 2014. For each patient, potential fracture of the nasal bone was evaluated by physical examination and computed tomography (CT) imaging. Patients were enrolled into the study for the presence of nasal bone fracture (with or without septal fracture). Exclusion criteria were made for tobacco use, history of chronic infectious sinusitis, or allergic rhinitis. A total 97 patients met the study criteria during the study period. With enrollment, each patient underwent an olfactory function test before and after the respective operation. A database was created for patient demographics, fracture etiology, concomitant injury, clinical finding, and radiographic evaluation. The CT imaging was used to classify each fracture as one of four nasal fracture types according to the Haug and Prather classification [7]. Type I fracture is defined by the fracture of inferior one half of nasal bone. Type II fracture is the fracture of entire nasal bone separated at the nasofrontal suture. Type III fracture is defined by the involvement of the frontal process of maxilla in addition to the nasal bone fracture. Type IV fracture consists of complex facial bones fractures that include nasal bones, frontal process of maxilla, nasal spine of frontal bone, and the ethmoid bone. Each fracture types can further be subclassified by the presence or absence of the septal fracture. All patients underwent closed reduction within 2 weeks of facial injury. Both of the nasal cavities were internally splinted using $4-\mathrm{cm}$ Merocel packing, which were removed on day 4 .

\section{Olfactory function assessment}

The olfactory function was assessed in a quiet, well-ventilated room, within the two weeks leading up to the fracture reduction and again at six months after operation. At each evaluation, the patient was examined using the Korean Version of the Sniffin' Sticks Test (KVSS) II, which evaluates for 16 odors familiar to the Korean population [20]. The test evaluates for olfactory threshold, discrimination, and identification [16]. In brief, the threshold is defined as the average of concentrations at which n-butanol (highest concentration 4\%, 1:2 serial dilution to 16 steps) is correctly identified four times in a row. In the discrimination test, a triple set of odorants (two of them are identical; the remaining odorant is unique) is presented, for which the subject must identify the unique odorant. The identification test evaluates the ability to identify an odorant among 4 given answers, and is performed for all 16 odorants. The result of each test is recorded as a score ranging from 0 to 16 , and the sum of these scores are used as the threshold, discrimination and identification (TDI) score. A subject is deemed to have "anosmia" for scores in the 0-20 range, "hyposmia" for 21-27, and "normosmia" for 28-48.

\section{Statistical analysis}

The preoperative and postoperative TDI scores were compared using the Mann-Whitney U test. For all calculations, a two-tailed $p$-value of $<0.05$ was considered statistically significant. All analyses were performed using the SPSS statistical software program (SPSS ver. 12.0, IBM SPSS Inc., Chicago, IL, USA).

\section{RESULTS}

The age of patients enrolled in the study ranged from 14 to 67 years, with a mean of 36.5 years. The nasal bone fractures were caused by motor vehicle accidents, incidental falls, physical altercation, sports-related injury, and occupational hazard. Per the Haug and Prather classification, the most common type of fracture was the Type I fracture $(58 / 97,59.7 \%)$ with septal fractures present in 28 cases (48.2\%). Type II fractures consisted of 19 cases (19.6\%) with approximately half of the patients having septal fracture $(10 / 19,52.6 \%)$. The remaining 20 cases were evenly divided between Type III and Type IV fractures (10 patients each at 10.3\%). Of the 97 patients, septal fractures were present in 51 patients $(51 / 97,52.6 \%)$ with the remaining 46 patients having purely bony fractures $(46 / 97,47.4 \%)$ (Table 1).

Olfactory dysfunction was frequent among the nasal fracture patients. Of the total, olfaction was within normal range of TDI 
Table 1. Distribution of nasal bone fracture type in 97 patients

\begin{tabular}{lccc}
$\begin{array}{l}\text { Fracture } \\
\text { type }\end{array}$ & $\begin{array}{c}\text { With fractured } \\
\text { septum }\end{array}$ & $\begin{array}{c}\text { Without fractured } \\
\text { septum }\end{array}$ & Total (\%) \\
\hline Type I & 28 & 30 & $58(59.7)$ \\
\hline Type II & 10 & 9 & $19(19.6)$ \\
\hline Type III & 7 & 3 & $10(10.3)$ \\
Type IV & 6 & 4 & $10(10.3)$ \\
\hline Total & 51 & 46 & 97 \\
\hline
\end{tabular}

a) The fracture type followed the Haug and Prather classification: Type I fracture is the fracture of inferior one half of nasal bone. Type II fracture is the fracture of entire nasal bone separated at nasofrontal surface. Type III fracture is the fractures of nasal bones and frontal process of maxilla. Type IV fracture is the fractures of complex facial bones including nasal bones, frontal process of maxilla, nasal spine of frontal bone and ethmoid bone.

Table 2. Distribution of olfactory function changes according to type of nasal fracture

\begin{tabular}{lccc} 
Fracure type $^{\text {a) }}$ & Normal & Hyposmia & Anosmia \\
\hline Type I & & & \\
With septal fracture & 18 & 12 & 0 \\
$\quad$ Without septal fracture & 18 & 10 & 0 \\
\hline $\begin{array}{l}\text { Type II } \\
\text { With septal fracture }\end{array}$ & 4 & 4 & 1 \\
$\quad$ Without septal fracture & 5 & 5 & 0 \\
Type III & 2 & 5 & 0 \\
With septal fracture & 2 & 1 & 0 \\
$\quad$ Without septal fracture & & & \\
Type IV & 2 & 4 & 0 \\
With septal fracture & 1 & 3 & 0 \\
Without septal fracture & $52(53.6)$ & $44(43.2)$ & $1(1.03)$ \\
\hline Total (\%)
\end{tabular}

a) The fracture type followed the Haug and Prather classification.

scores for 52 patients (53.6\%), whereas 44 patients (45.2\%) demonstrated hyposmia. A single patient demonstrated clinical anosmia with TDI of less than 12. This particular patient had suffered a complete separate of the nasal bone with septal fracture (Table 2).

Our study evaluated TDI scores before and after nasal bone reduction for Type I and II fractures. Among patients with Type I fracture $(n=58)$, the mean TDI score was 31.3 and 29.9 for preoperative and 6-month KVSS II tests, respectively $(p>0.05)$. In the subset of Type I fractures with septal fracture $(n=28)$, the scores were 29.4 and 28.5, respectively. In patients with Type I fractures with intact septum $(n=30)$, the scores were 33.1 and 31.2, respectively. The decrease in TDI scores was not significant in either of the subset groups ( $p>0.05$ for both) (Fig. 1).

Among patients with Type II fractures $(n=19)$, the mean TDI

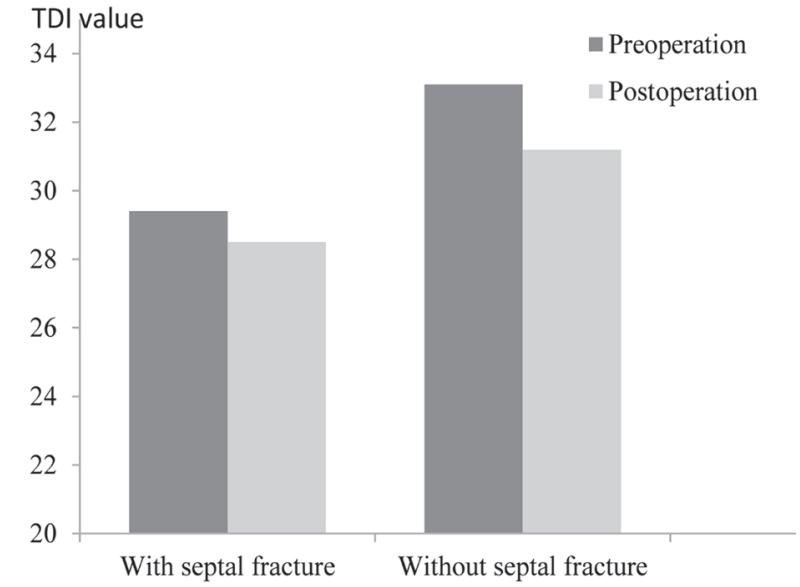

Fig. 1. Olfactory function after Type I fracture (KVSS test II). TDI, threshold, discrimination and identification; KVSS, Korean version of Sniffin' Sticks test.

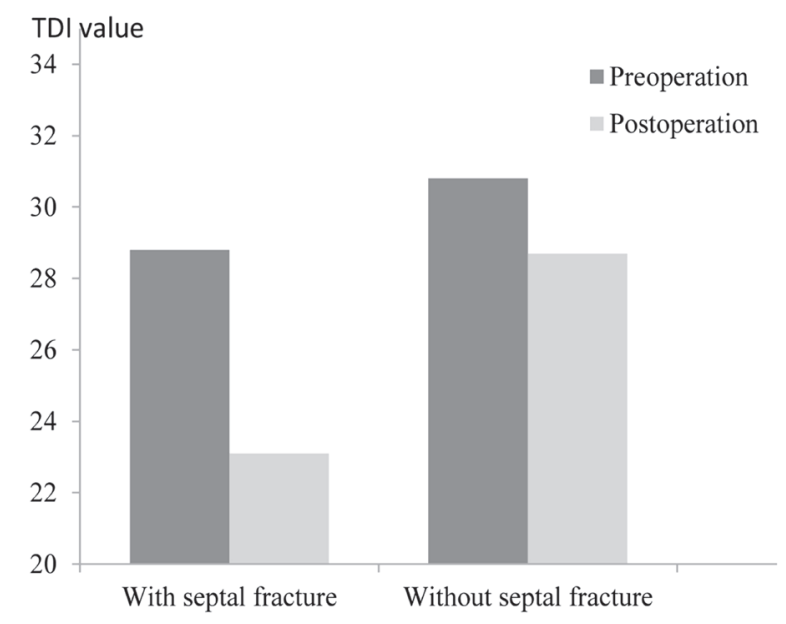

Fig. 2. Sense of smell in patients who underwent closed reduction for Type II fracture (KVSS test II). TDI, threshold, discrimination and identification; KVSS, Korean version of Sniffin' Sticks test.

scores were 29.9 and 26.0 at preoperative and 6 month evaluations, respectively $(p>0.05)$. In the subset of Type II fractures with septal fracture $(n=9)$, the scores were 28.1 and 23.1, respectively. This decrease was statistically significant $(p=0.02)$. In patients with Type II fractures with intact septum $(n=10)$, the scores were 30.8 and 28.7, respectively $(p>0.05)$ (Fig. 2).

In Type III and IV fracture groups, the TDI scores did not significantly differ between preoperative and postoperative olfactory function test $(p>0.05)$ (data not shown). 


\section{DISCUSSION}

The nose is frequently injured in facial trauma due to the protruding shape and the central location. It is composed of cartilaginous framework anteriorly and inferiorly, and is supported by facial bones posteriorly and superiorly. Despite the abundance of mechanically pliable cartilage, the nasal bones usually are fractured due to facial trauma $[2,14]$. Various classification schemes exist for nasal bone fractures. Harrison classified nasal bone fractures based on the combination of fractured bones with/without displacement. Stranc and Robertson [21] focused on the direction of force resulting in nasal fracture and clinical assessment. In our study, the nasal fractures were classified according to the Haug and Prather classification [7], which distinguishes nasal fractures by the involvement of bony fractures and by the presence or absence of septal fracture.

Olfactory dysfunction can result from injury to any portion of the olfactory tract, and occurs most frequently with nasal bone fractures. In most situations, posttraumatic olfactory dysfunction is a consequence of the distortion of sinus tract. Nasal bone or midface fractures can disrupt the normal airflow and prevent odorants from reaching the olfactory nerve, resulting in conductive loss of smell [18]. Soft tissue injuries within the nasal cavity leading to mucosal or septal hematoma, edema may distort anatomy and therefore function [22]. It also comes from the direct injury of olfactory nerve or injury to any central component or connection of olfaction [10]. Depending on the study, the incidence of posttraumatic olfactory dysfunction has been reported from 5\% to over $80 \%$. Nasal bone fractures can lead to complete or partial loss of olfactory function despite adequate reduction [11-19,23].

Previous studies have focused primarily on olfactory dysfunction associated with complex head trauma [14,16]. These studies have found that olfactory dysfunctions are more likely in patients who have experienced severe head trauma with loss of consciousness and that specific sites of injury correlate to decreased olfaction, including skull base, frontal lobes, nasal bones, and the upper jaw $[14,15,17,19,24]$.

Among the 97 patients in our study, posttraumatic olfactory dysfunction was observed in 45 patients (46.4\%). Hyposmia was extremely common in our patient population. The observed ratio between normosmia and hyposmia increased with the severity of fracture according to the Haug and Prather classification. Though this association between fracture type and frequency of fracture was not statistically significant, we interpret this to be a reflection of the sample sizes being smaller for more severe fractures.

In previous studies, spontaneous recovery of olfaction has been recorded in patients with facial bone fractures. Among patients with posttraumatic anosmia, studies have found that one-third of patients eventually recover a degree of olfactory function $[22,23]$. In most cases, spontaneous recovery of posttraumatic olfactory dysfunction occurs within the 6 months following the traumatic episode. Although recovery of olfaction has been reported to be delayed as much as 7 years after injury, the probability of recovery beyond 2 years post-injury is very low [25].

In theory, posttraumatic olfactory dysfunction due to loss of air conduction should resolve with fracture reduction and cessation of mucosal edema. However, our olfactory assessment using the Korean version of Sniffin' Sticks test revealed that fracture reduction was not associated with improvements in the mean TDI score in Type I or Type II fractures. In fact, we were surprised to observe the trend for a decrease in the objective scores at 6 months after the operation. Though not all of the results were statistically significant, we again believe this to be a problem of the sample size. In the subset of Type II fractures with concomitant septal fracture, the mean posttraumatic TDI score decreased from 28.8 points prior to operation to 23.1 point at 6 months, which represents a transition from normosmia (greater than or equal to 28 points) into hyposmia (above 20 and below 28 points). These findings suggest that the nasal fracture itself is most likely not the sole cause of olfactory dysfunction. The continual worsening of olfactory sensitive and specificity may be due to damage to the olfactory nerve ending via surgical instrumentation of the nasal mucosa, nasal packing damage, persistent mucosal edema from chronic local infection, or postoperative viral infection such as herpes, influenza, and hepatitis viruses [26].

Our study has several limitations. First, our sample sizes were too small for subgroup analysis for more severe fractures (Types III and IV), though our data suggests that olfactory dysfunctions 
are probably more common and/or worse in more severe fractures. Second, we cannot say with definite certainty that patients who were found to have hyposmia were normosmic prior to injury because there is no retrospectively way to evaluate olfaction in an objective way. However, we find this to be a relatively safe assumption. Third, we did not assess olfactory function beyond the 6 month period, which could potentially reveal improvement over the 2 year period following trauma.

In conclusion, our study has revealed two alarming trends regarding post-nasal fracture olfactory dysfunction. First, our study demonstrated that almost half (46.4\%) of nasal fracture patients experience posttraumatic olfactory dysfunction. Second, closed reduction of these fractures does not lead to improvements olfaction at 6 months, which suggest that olfactory dysfunction is probably due to factors other than the fracture itself (i.e., soft tissue injury). Olfactory dysfunction can significantly impair activities of daily living and decrease the quality of life in patients after nasal fracture. As such, the association should be further explored between injuries that lead to nasal fracture and the mechanism behind posttraumatic olfactory dysfunction.

\section{REFERENCES}

1. Basheeth N, Donnelly M, David S, Munish S. Acute nasal fracture management: a prospective study and literature review. Laryngoscope 2015;125:2677-84.

2. Kucik CJ, Clenney T, Phelan J. Management of acute nasal fractures. Am Fam Physician 2004;70:1315-20.

3. Mondin V, Rinaldo A, Ferlito A. Management of nasal bone fractures. Am J Otolaryngol 2005;26:181-5.

4. Hwang K, You SH, Kim SG, Lee SI. Analysis of nasal bone fractures: a six-year study of 503 patients. J Craniofac Surg 2006;17:261-4.

5. Rohrich RJ, Adams WP Jr. Nasal fracture management: minimizing secondary nasal deformities. Plast Reconstr Surg 2000;106:266-73.

6. Rhee SC, Kim YK, Cha JH, Kang SR, Park HS. Septal fracture in simple nasal bone fracture. Plast Reconstr Surg 2004;113:45-52.

7. Haug RH, Prather JL. The closed reduction of nasal fractures: an evaluation of two techniques. J Oral Maxillofac Surg 1991;49:1288-92.

8. Murray JA, Maran AG, Mackenzie IJ, Raab G. Open v closed reduction of the fractured nose. Arch Otolaryngol 1984;110:797-802.
9. Park HK, Lee JY, Song JM, Kim TS, Shin SH. The retrospective study of closed reduction of nasal bone fracture. Maxillofac Plast Reconstr Surg 2014;36:266-72.

10. Ridder GJ, Boedeker CC, Fradis M, Schipper J. Technique and timing for closed reduction of isolated nasal fractures: a retrospective study. Ear Nose Throat J 2002;81:49-54.

11. Hwang K, Yeom SH, Hwang SH. Complications of nasal bone fractures. J Craniofac Surg 2017;28:803-5.

12. van Damme PA, Freihofer HP. Disturbances of smell and taste after high central midface fractures. J Craniomaxillofac Surg 1992;20:24850 .

13. Fan LY, Kuo CL, Lirng JF, Shu CH. Investigation of prognostic factors for post-traumatic olfactory dysfunction. J Chin Med Assoc 2015;78:299-303

14. Haxel BR, Grant L, Mackay-Sim A. Olfactory dysfunction after head injury. J Head Trauma Rehabil 2008;23:407-13.

15. Dursun E, Battal B. Olfactory dysfunction following nasal trauma. Int J Otorhinolaryngol 2008;10:1-4.

16. Coelho DH, Costanzo RM. Posttraumatic olfactory dysfunction. Auris Nasus Larynx 2016;43:137-43.

17. Yousem DM, Geckle RJ, Bilker WB, Kroger H, Doty RL. Posttraumatic smell loss: relationship of psychophysical tests and volumes of the olfactory bulbs and tracts and the temporal lobes. Acad Radiol 1999;6:264-72.

18. Renzi G, Carboni A, Gasparini G, Perugini M, Becelli R. Taste and olfactory disturbances after upper and middle third facial fractures: a preliminary study. Ann Plast Surg 2002;48:355-8.

19. Costanzo RM, Miwa T. Posttraumatic olfactory loss. Adv Otorhinolaryngol 2006;63:99-107.

20. Hong SC, Yoo YS, Kim ES, Kim SC, Park SH, Kim JK, et al. Development of KVSS test (Korean version of Sniffin' sticks test). Korean J Otolaryngol 1999;42:855-60.

21. Stranc MF, Robertson GA. A classification of injuries of the nasal skeleton. Ann Plast Surg 1979;2:468-74.

22. Costanzo RM, DiNardo LJ, Zasler ND. Head injury and taste In: Doty RL, editor. Handbook of olfaction and gustation. New York: Marcel Dekker; 1995. p. 775-83.

23. Welge-Lussen A, Hilgenfeld A, Meusel T, Hummel T. Long-term follow-up of posttraumatic olfactory disorders. Rhinology 2012;50:67-72.

24. Kalavrezos ND, Graetz KW, Eyrich GK, Sailer HF. Late sequelae after high midface trauma. J R Coll Surg Edinb 2000;45:359-62.

25. Costanzo RM, Becker DP. Smell and taste disorders in head injury and neurosurgery patients. In: Meiselman HL, Rivlin RS, editors. Clinical measurement of taste and smell. New York: Macmillan; 1986. p. 565-78.

26. Kimmelman CP. The risk to olfaction from nasal surgery. Laryngoscope 1994;104:981-8. 